\title{
THE PLACE OF OCCUPATIONAL. THERAPY IN REHABILITATION
}

\author{
By S. CYNKIN, Dip. O.T. (Rand.) and J. HARRISBERG, Dip. O.T. (Rand.).
}

$\mathbb{P}$ EHABILITATION has been defined as "the restoration of the handicapped to the fullest physical, mental, social, vocational and economic usefulness of which they are capable." Occupational Therapy plays an important part in the physical and mental aspects of rehabilitation, and is also able to assist in pre-vocational guidance and preparation of the patient for contact with the outside world.

- As all these aspects of Occupational Therapy cannot be dealt with in one article, it is proposed to discuss only the "physical" rehabilitation of the patient. However, although the term "physical" is used, it must be stressed that the essence of Occupational Therapy is to combine actual physical movement with treatment of the psychological factors associated with every case of disability.

Indications for Occupational Therapy.

1. Nervous System-disease and injury.

(a) Upper Motor Neurone Lesions-particularly Residual Hẹmiplegia, Cerebral Palsy, Paraplegia;

(b) Lower Motor Neurone Lesions-with particular reference to Anterior Poliomyelitis, Peripheral Neuritis and Peripheral Nerve Injuries;

(c) Conditions involving Loss of Co-ordination-as in Athetosis, Chorea, post-operative cerebellar tumours.
2. Bones, and Joints-disease, injury and surgical repair e.g. Rheumatoid Arthritis and Osteo-arthritis, Congenital deformities, Fractures, Hip Arthroplasty.

3. Muscles and Tendons-disease and injury and surgical repair e.g. Muscular Dystrophy, Tendon Sutures and Transplants.

4. Circulatory and Respiratory Systems-e.g. Congestiye, Cardiac Failure, Asthma, etc.

\section{Plastic Surgery and Burns.}

Mention must also be made of the rehabilitation of Amputees, a somewhat specialised field, where particularly in the U.S.A., the function of the Occupational Therapist is primarily to train patients in the performance of everyday skills by means of their prostheses.

\section{Aims of Occupational Therapy.}

(a) The basic aim is to provide a means of assisting in the restoration of function through the medium of crafts or other motivated activity, thus distracting attention from the disability. The patient whose mind is occupied with an interesting activity is more receptive to treatment, for, being more relaxed, fear of pain on movement is minimised.

(b) Specific Aims are governed by the symptomatology of the cases to be treated-examples are tabulated below:

\begin{tabular}{|c|c|c|c|}
\hline Anterior Poliomyelitis & Paraplegia & Burns & $\begin{array}{l}\text { Cerebral Palsy } \\
\text { (Athetoid) }\end{array}$ \\
\hline $\begin{array}{l}\text { 1. Re-education of muscle } \\
\text { function-graded from } \\
\text { assistance-resistance. } \\
\text { 2. To establish new asso- } \\
\text { ciation pathways. } \\
\text { 3. To. maintain blood } \\
\text { supply to muscles. } \\
\text { 4. To encourage concen- } \\
\text { tration and general co- } \\
\text { ordination of move- } \\
\text { ment. } \\
\text { 5. To prevent depression } \\
\text { and morbid introspec- } \\
\text { tion. }\end{array}$ & $\begin{array}{l}\text { A. Where complete section } \\
\text { of cord. } \\
\text { 1. Strengthening of torso } \\
\text { and upper extremities } \\
\text { for crutch walking. } \\
\text { 2. Training, when neces- } \\
\text { sary, for a sedentary } \\
\text { occupation whereby } \\
\text { patient can earn a live- } \\
\text { lihood. } \\
\text { B. Where recovery of lower } \\
\text { limbs is likely : } \\
\text { 1. Re-education and re- } \\
\text { laxation of spastic mus- } \\
\text { cles of lower limbs. }\end{array}$ & $\begin{array}{l}\text { 1. To prevent contrac- } \\
\text { tures. } \\
\text { 2. To increase range of } \\
\text { active movement and } \\
\text { improve circulation. } \\
\text { 3. Where the area of the } \\
\text { chest is involved-chest } \\
\text { expansion and preven- } \\
\text { tion of deformities. }\end{array}$ & $\begin{array}{l}\text { 1. Train new brain path- } \\
\text { ways to take over the } \\
\text { function of the dam- } \\
\text { aged areas. } \\
\text { 2. Afford the child oppor- } \\
\text { tunities for normal de- } \\
\text { velopment. } \\
\text { 3. Relaxation. } \\
\text { 4. Improve grasp and co- } \\
\text { ordination. } \\
\text { 5. Train performance of } \\
\text { every day skills, e.g. } \\
\text { dressing. }\end{array}$ \\
\hline
\end{tabular}




\section{CASE HISTORY I}

Medical Prescription: Miss X. Age: 26. Date: 16/1/53. Diagnosis: ANTERIOR POLIOMYELITIS.

History: Poliomyelitis is of approximately 6 weeks' duration. Both legs affected-left leg very weak at hip and knee, and there is only a flicker in pesonei at ankle. Right leg improving rapidly. Slight weakness spinal muscles, right side.

Movements Required: Of left leg mainly. Patient must be treated in lying position due to weak spinal muscles.

Psychological Aspect of Case: Patient is an intelligent young woman, very depressed at the moment.

Treatment and Progress :

17/1/53. Movements left leg tested:

KNEE : Quadriceps-very weak (vastus medialis absent).

Hamstrings-flicker.

HIP : Flexors-weak.

Glutei-very, weak.

Tibialis anterior-absent.

Psychological aspect: Patient weeps easily-feels she will never walk again.

It was decided to concentrate on quadriceps only at first, as all muscle of leg were too weak to work actively in combination.

Craft Analysis: WEAVING was chosen as being most suitable for leg movement, especially while patient was in bed. A small, simply-operated loom was clamped onto a bed table across the patient, so she was able to see her work while lying flat in bed. A lead was taken from the loom through a pulley to a sling around the knee in such a way that part of the weaving process was carried out by quadriceps contraction. The rest of the weaving process was completed by hand and arm movement.

A foot-board at the end of the bed prevented "footdrop" and acted as a lever for the leg.

Work Period: Patient worked for 5 minutes, then complained of fatigue.

25/1/53. Patient worked for 30 minutes. Much more cheerful. Has confessed that she thought in the beginning that Occupational Therapy had been prescribed because she was "mental."

$7 / 2 / 53$. Improvement in psychological outlook has helped patient's concentration and hence re-education of neuromuscular function. Now able to produce two movements while weaving-extension and flexion of knee. Quadriceps still weak, vastus medialis-flicker apparent.

$17 / 3 / 53$. Patient permitted to be treated sitting up in department. On examination left leg:

Quadriceps--weak:

Hamstrings

Glutei-very weak

Tibialis Anterior-query flicker.

Weaving again chosen, this time on large foot-power loom with special adaptation for flexion and extension of both knees, the right leg thus assisting the weaker left leg.

In the Physiotherapy Department the patient is learning to walk with two sticks, and a caliper with a pelvic band.

$2 / 4 / 53$. Flexion and extension hip and knee im-

proved. Left leg now working independently of right.

$11 / 4 / 53$. Resistance :

3-lbs. to quadriceps-added to loom.

3-lbs. to hamstrings

In addition to weaving, patien" now works on a bicycle fret saw for strengthening and co-ordination of all hip and knee movements.

$13 / 5 / 53$. Patient worked on treadle sewing machine for assisted movement of left tibialis anterior, and continued with bicycle saw and 5-lbs. resistance to quadriceps and 5-lbs. to hamstrings, while weaving.
Patient now has full daily programme as follows:

8.30 -9.30 a.m.: Physiotherapy-general exercises.

9.30-10.30 a.m. : Occupational Therapy-quadriceps and hamstrings exercise through weaving.

10.30-11.30 a.m.: Games Therapy-Physiotherapist and Occupational Therapist working in conjunction. Games are played with a group of patients, all Anterior Poliomyelitis or Paraplegia, cases. Among other games, darts are used for balance and co-ordination, carpet bowls for knee and hip movement.

12 noon-1.30 p.m.: Lunch and rest period.

1.30 p.m. -2.30 p.m.: Physiotherapy-re-education of walking.

2.30 p.m.-4 p.m.: Occupational Therapy-bicycle saw and treadle machine.

$3 / 8 / 53$. Continued improvement. Quadriceps and

Glutei much stronger. Resistance on loom increased to: Quadriceps-7-1bs.

Hamstrings-7-lbs.

$1 / 3 / 54$. Patient has gone on leave for personal reasons and because it is felt she is becoming overhospitalized. Now walking with only one stick and spring support for weak tibialis anterior. Will return in 3 months' time.

\section{CASE HISTORY II.}

JOHANNES, P. Age: 24 years. Admitted to hospital $25 / 1 / 54$ at 7.45 a.m. Was stabbed in the back $24 / 1 / 54$ at 6 p.m.

C.O.E. (1) Stab at level T6, just left of mid-line.

(2) Anaesthesia below T10.

(3) Flaccid paralysis of both legs.

(4) Has passed no urine since stabbed.

By $29 / 1 / 54$ spasticity had developed in the legs. Abdominal reflexes absent. Bladder training commenced.

$12 / 2 / 54$. An Occupational Therapy card sent to the Department requested strengthening of both upper limbs for crutch walking. Treatment to be commenced in bed.

\section{Craft Analysis :}

Crafts giving bilateral movement and to which resistance can be added are most valuable in a treatment of this nature e.g. weaving and cord-knotting.

Craft chosen for Johannes-Cord-knotting.

The emphasis here is an extension of elbows and strengthening of grip.

The patient was treated in a lying position with one pillow for the head, the cord-knotting being attached to the overhead beam in such a manner that the knotting could not be done without full extension of the elbows.

By means of a weight and pulley circuit, with slings attached to the hands, 2-lbs. resistance was given to elbow extension. The weight and time factors were graded as follows :

3 minutes work period-2 minutes rest period

for 45 minutes. Work period was gradually built

up to- 6 minutes, then when weight was graded to

3-lbs. On each triceps, the work period was reduced

to 3 minutes again, and progressed in same manner.

19/3/54. Patient allowed to attend Occupational Therapy Dept.

A special weaving loom has been adapted for all Paraplegia cases, to give the required muscle strengthening in the sitting position. Johannes attended every morning for 30 minutes, this time being gradually increased to a maximum of $1 \frac{1}{2}$ hours.

Patient attended Physiotherapy in the afternoon. For first week no resistance given, as the patient had to get accustomed to being up. 
$24 / 3 / 54$. The following weights were applied to the loom to give the necessary resistance :

(1) Triceps-3-lbs. each.

(2) Latissimus Dorsi-6-lbs.

Rhomboids
Trapezius
Pectoralis . ",

An overhead beater is also attached to the loom to give the necessary strengthening.

$1 / 4$ is4. Weights graded to :

(1) Triceps-4-lbs. each.

(2) Latissimus Dorsi, etc.-16-lbs.

When the patient attended the department, Pre-Vocational Träining was also commenced. Johannes expressed an interest in cobbling and he started attending classes in the morning after his remedial treatment and a break for tea.

19/5/54. Patient started crutch-walking. Remedial Occupational Therapy discontinued, and emphasis of treatment is now on re-vocational training.

\section{CASE HISTORY II.}

J.S.-Non-European child aged 7, admitted 21/4/54 with 2nd degree burns of chest and axillae.

Remedial Occupational Therapy was requested 2 weeks. after admission when sufficient granulation tissue had formed to warrant active movement.

At the same time Physiotherapy treatment was started.
C.O.E.
Flexion :
Right Shoulder
Left Shoulder
Extension :
$80^{\circ}$
$30^{\circ}$
$100^{\circ}$
$\therefore 42^{\circ}$
$90^{\circ}$

These were the only movements that could be measured because of limitation by heavy bandaging.

\section{Treatment' in Bed :}

1. The first obstacle to be overcome at this stage was fear of pain. 'It was found that the child was-afraid to move, even within the limits of pain. An attempt was made to gain his confidence by giving him a brightly-coloured soft ball-and before long the natural inclination to play ball overcame the initial fear of movement. In this way, play therapy was started, incorporating the required range of gentle active movement in a series of different ball games.

2. Due to pain, the child was developing a bad posture-Kyphosis and a mild Scoliosis. To prevent this deformity simple cord-knotting with brightly-coloured rug wool was chosen as a craft as this provided :

(a) chest expansion;

(b) bilateral active movement of upper limbs.

TREATMENT IN DEPARTMENT commenced 5/5/54. The child was brought down every afternoon, having attended Physiotherapy in the morning, and having had a good rest period in the interval.

.The following movements were concentrated on during treatment in the dept.

1. Abduction, Flexion and External Rotation of Both Shoulder Joints.

(a) Play therapy was continued, using a larger ball and concentrating mainly on overhead games against a wall using first both arms together and then each arm individually.

Careful supervision was necessary to ensure that the correct movements were being obtained.

(b) At this stage the child was also able to play darts, using right and left arms alternatively. The dartboard was suspended above shoulder level in order to ensure shoulder movements during the game.

\section{Chest expansion.}

To mobilise the thoracic cavity and to encourage deep breathing, blowing games were used e.g. blow-football, bubble-blowing, and blowing paper windmills.

These games were played with other children to foster the spirit of competition and to divert the attention from the true aims of these games.

3. Flexion, Extension of Shoulders and Chest Expansion.

Block printing was a craft chosen to give these particular movements.

(a) because the craft consisted of using bright colours which most children enjoy;

(b) because of its adaptability by a horizontal bar 24-in. long, which is attached to the roller handle. Both hands were used to hold the ends of this handle when rolling the paint off the glass and onto the block, and in this way the required movement of the shoulders were obtained.

By varying the height of the chair on which the patient sat, the range of movement was graded according to the requirements.

Measurements taken on $17 / 5 / 54$ i.e. two weeks later. proved the following:

Extension :
Flexion :

Abduction :

Right Shoulder $8^{\circ}$ improvement $6^{\circ}$

External rotation: Full limited.
Left Shoulder $6^{\circ}$ improvement $4^{\circ}$ - Full very limited
Though a completely full range of movement had not yet been obtained the patient was discharged from the Ward, due to the acute shortage of beds in the Hospital. Attending 3 times weekly as an out-patient for both Physiotherapy and Occupational Therapy treatment, the child has been making steady progress to date.

\section{CASE HISTORY IV.}

Name: P.O. Age: $6 \frac{3}{4}$ years.

Diagnosis: Tension athetoid with auditory perception difficulty.

This patient was referred for treatment because of excessive abnormal movements.

Delivery at Birth: Normal, no instruments, jaundice, annoxia or convulsions. Labour 36 hours. Parents both well. Birth weight: $9 \frac{1}{2}$ lbs. First child.

The mother noticed:
1. Baby very restless.
2. Difficulty in sucking.
3. Unable to sit at 9 months.
4. Crawled at 2 years.
5. Walked at 3 years.
6. Spoke sentences at 4 years.

C.O.E.

1. Physical: General health and posture good. Child drools and has difficulty with breathing. His gait is shuffling.

He is able to grasp large, small and medium sized objects. His grasp is not developed and needs improvement. He must learn to use his finger tips and not his palm.

His co-ordination is poor-he does not reach or return directly.

Both hands are affected-the left to a lesser degree. $\mathrm{He}$ is left-handed. 
2. Mental: At a clinic held in 1952 the child was assessed as being mentally retarded.

Since treatment began in October 1953 he has improved greatly in writing and general school work.

He has an excellent ability to concentrate and follow instructions, and despite adequate testing, on his school work it is felt his 1.Q. is average.

3. Speech: Marked limitation in basic functions. Articulatas are poorly utilized.

\section{Treatment :}

By constant repetition of specific movements e.g. grasping, it is hoped to train new brain pathways. Occupational Therapy and the general school programme give the child everyday experiences and opportunities for normal development.

There are various methods of achieving relaxation, a very satisfactory method is one of a calm, friendly relaxed approach on the part of the therapist, this is transferred to the patient.

1. Weaving: (a) on a frame which involves graspthe shuttle is made a suitable size to involve use of all the fingers in flexion.

(b) co-ordination - the shuttle is darned in and out of the warp threads thus involving slow controlled movements.

(c) elbow flexion and extension - as the shuttle is drawn out of the warp. - This teaches the same arm movement required in feeding.

(d) abduction of the fingers, and extension of the wrist in beating down the weft threads. This child has some tension and requires movement at the wrist joint.

2. Constructional toys such as "Teachem" toys are given for co-ordination and grasp.

3. Skills: The patient is to button up and unbutton large buttons on a frame.
4. Feeding: The child practises feeding in front of a mirror. Being unable to supinate the child is taught to flex his elbow with the wrist in pronation, to bring the spoon to his mouth. The mirror assists him to reach his mouth directly.

5. Drooling is checked by constantly reminding him to keep his mouth closed. He is given gum and sweets to check the flow of saliva. This carried out in conjunction with the speech therapist.

$\mathrm{He}$ is a co-operative and keen patient. Unfortunately, due to lack of time both on the part of the therapist and the child, who has a full programme of therapy and school, he is unable to participate in group activities, which would be particularly beneficial for-

1. Art and finger painting-which gives opportunity for self-expression and finger dexterity.

2. Games-this promotes a healthy spirit of competition and an outlet for excess energy not forgetting the normal desire of children to play.

No child is treated in isolation. Each therapist and teacher work as a closely knit team to equip these children to take their place in society, despite their handicap.

Observation :

As it can be seen from the treatment of the aforesaid case histories it is impossible to draw a well defined barrier between the function of the various medical auxiliariesfor upon the closer co-operation only, between the medical staff, physiotherapist, speech therapists, social worker, teachers and the occupational therapist, depends the success of the Rehabilitation of the patient.

Thanks:

We would like to thank the Occupational Therapy Departments at the General Hospital, Johannesburg, Baragwanath Non-European Hospital, Edenvale Hospital and the Forest Town School for Cerebral Palsy Children for their co-operation in providing the case histories.

\title{
THE HABILITATION OF - THE CEREBRAL PALSIED CHILD
}

\author{
By \\ F. M. TRAGOTT-VORWERG (Principal). SOPHIE LEVITT (Head Physiotherapist) \\ Forest Town School for Cerebral Palsy.
}

TT cannot be denied that Cerebral Palsy and its treat1 ment presents a growing problem all over the world today, not least in South Africa.

From about the mid-nineteenth century, when Dr. William Little gave some attention to "Spastics," Cerebral Palsy cases were all labelled Little's Disease, and those dealing with it, accepted an associated mental deficiency with a hopeless prognosis. Only in recent years has it been realised that the Cerebral Palsied had potentially greater abilities than hitherto suspected.

Much of the pioneering work in this field began in the U.S.A., under the direction of such as Crothers, Phelps, Fay, Perlstein and others. It was emphasized that a damaged brain did not necessärily indicate mental deficiency, and that the condition is manifest in several forms, of which Spasticity is only one.

Definition.

Cerebral Palsy is commonly defined as a condition characterised by paralysis, weakness, inco-ordination, or any other aberrations of motor functions, due to-malfunction of the motor centres of the brain.
The types of Cerebral Palsy are described according to clinical findings rather than to aetiology, and the following classifications are generally accepted:

\section{Spasticity.}

The cases in this group may be quadriplegias, paraplegias, hemiplegias and the rarer monoplegias and triplegias.

The main features reveal postural deformities, e.g. internally rotated, abducted position of the legs; increased tendon reflexes and the presence of the hyperactive stretch reflex. Thus, when a muscle group contracts, the stretched antagonist contracts simultaneously instead of relaxing to allow a smooth normal movement, as referred to in Sherrington's "Law of Reciprocal Innervation."

\section{Athetosis.}

These cases are commonly "quadriplegias" and also hemiathetoids have been described. Athetoids exhibit involuntary unpatterned movements, disturbances in balance, co-ordination and often tone. 